2017-04-19

\title{
Student life - Taking a healthy approach to social networking
}

Jones, Ray

http://hdl.handle.net/10026.1/11557

10.7748/ns.31.34.33.s39

Nursing Standard

RCN Publishing Ltd.

All content in PEARL is protected by copyright law. Author manuscripts are made available in accordance with publisher policies. Please cite only the published version using the details provided on the item record or document. In the absence of an open licence (e.g. Creative Commons), permissions for further reuse of content should be sought from the publisher or author. 


\section{Article published in RCNi Careers Guide 2016 co-authored by third year nursing student Julie Woolman and recently graduated nurse Megan Betts.}

\section{Using social media to stay fit and healthy}

Ray Jones is professor of health informatics, Julie Woolman a third year adult nursing student, and Megan Betts a recent graduate of the School of Nursing and Midwifery at Plymouth University. Plymouth University has included 'Digital Professionalism' in its curriculum for first year students since October 2014. Megan was already leading in the use of social media and has run Tweetchats for @Nurchat. Julie has championed use of Twitter, helping other students, and is one of two student tweeters for @WeNurses. This article considers social media and includes examples from Julie and Megan of how they use social media in their own efforts to stay fit and healthy while dealing with the pressures of nursing.

Maintaining a good work-life balance as a nurse, given the range of other commitments that most have, can be difficult. It may seem almost contradictory to suggest that social media is part of the answer given that many see it as a 'thief of time' and possibly one of problems of modern life. But there are various ways to keep your social media under control and to use it in a way that helps and not hinders.

\section{Controlling your social media}

Various authors have suggested how to control your social media rather than letting it control you. As social media changes rapidly it is worth looking for the date on what you are reading. The main advice must be that all social media and your devices can be turned off. You can't concentrate on your essay - or on your yoga - if Twitter or Facebook notifications is bleeping all the time. Decide how much time each source of information is worth and stick to your limits. The box summarises six points from one source (http://www.womensagenda.com.au/guilt-free-zone/health/item/3621-six-ways-to-controlsocial-media-before-it-controls-you (Feb 2014).

6 ways to control social media before it controls you

1. Turn off notifications.

2. Delete your social media apps.

3. Have a one-day social media detox.

4. Do a cull.

5. Limit your online time.

6. Use your time effectively.

\section{Peer support using social media}

Nursing students approaching graduation or those just entering the profession can find life quite stressful. Another article in this RCN publication, describing the benefits of using Twitter for continuing professional development, mentions how online Twitter communities such as@WeNurses and @Nurchat give professional and emotional support. Although limited by 140 characters and the generality of what can be said, many of our students use 
Twitter to start to take on the role of nurse and are delighted (see box below) to discover how willing colleagues are to offer encouragement and support online.

- That glorifying moment when someone asks you what you do now and you reply 'I'm a student nurse'

- Yes I agree, the cohort is great, I feel we will all be helping each other

- Knowing that every day at uni is making my career possible to help people with mental health problems \#WorldMentalHealthDay \#studentnurse

- @NurChat definitely a help! I'm a Twitter convert! So much interesting info on here that will help me with my nursing course! \#studentnurse

- Always worth asking for \#help and \#support on anything you don't understand. Never be alone, we are a \#nursingteam

- Surprised by the advantages and opportunities Twitter can bring us nurse students. \#healthcarecommunity@WeNurses@NurChat@NursingTimes

- I've been a \#StudentNurse on twitter for less than two hours and already I can so excited as the support and community on here! @WeNurses

\section{Research into sharing}

How to use 'online' to help cope is also the focus of various research projects. For example, StorySHOP - Storytelling for Social and Health Care Workers Professional Identity Development - is developing a digital storytelling (DST) based training programme (http://storyshop-llp.eu/resources/). Using video online to 'tell a story' has been widely used for patients and people living with a long term condition (e.g. Healthtalk Online (http://www.healthtalk.org/ ), but the idea of StorySHOP is for nurses and other healthcare professionals allowing them to deal with stressful professional situations by telling their personal story. Of course any nurse talking online about work experiences must carefully consider issues not only of confidentiality but also their own work position [1].

\section{Practical uses of social media in healthy living}

But as well as the emotional support of talking and sharing online, social media can be a route to planning and managing exercise, diet, and getting out and about. Julie describes how she used it to establish a 'nursing fitcamp':

In April 2015 a Facebook friend posted that she had been attending a fitness session for several weeks and I discussed it with a group of nursing students the following day. Through social media messaging I contacted the personal trainer who ran the sessions and we ended up talking about how we could run fitness sessions just for student nurses. A Facebook group was set up and I started to run weekly events from the page, which enabled people to book onto sessions. The personal trainer wanted to name the group fitness sessions and 'student nurse fitcamp' was born.

After several months of running successful student nurse fitcamps I came across the Plymouth University Student Union Motivate Generate Activate (https://www.upsu.com/sports/mga/events/) (MGA) project on Twitter. The MGA project was set up to support students to do sporting activities and through Twitter I contacted the University's sports MGA support worker and had a meeting with her. She loved the idea of healthcare professionals getting together to keep fit and advised me that the MGA project could subsidise the fitness sessions so we could encourage more student nurses to join in.

With funding implemented the numbers attending the fitcamp sessions reached 29 people. This included students from all 3 years of the degree, through promoting Student Nurse Fitcamp on Twitter, 3rd year student nurses became regular attendees as well as people who were about to start their Nursing degrees 
course. The original personal trainer moved out of the area, but the student nurse fitcamp, which is now renamed Student Nurse and Healthcare professionals bootcamp, continues with a new personal trainer, to train students so they can keep fit be role models for patients when in practice.

We encourage our students for their professional social media accounts to use Twitter because of its very open nature and the large nursing community already there (eg @wenurses and @nurchat), but different social media may be preferred for other uses. Most students are of course also on Facebook and Instagram is also popular. Megan describes why and how she use Instagram for her social, health and wellbeing:

Although I use Twitter a lot for my professional work, I predominately use Instagram because it is less 'noisy' and photos are a great way to engage with your social network. This is a great way to share tips with others who have a passion for health and wellbeing. For example, personal journeys and motivational stories and posts are a great way to share similar interests and build relationships with people. Health, wellbeing, yoga, clean eating and fitness is what I am passionate about and therefore reading and sharing posts and blogs with like-minded people means I can learn about events in nearby areas. Lots of the people I met within health and wellbeing I met online before meeting in person. This has led to opportunities both on the professional side (further education and learning), but also in other aspects of my life (fitness videos, modelling, health blogs etc).

\title{
Staying safe online and offline
}

There are of course concerns about meeting people that you have met online but there are numerous guidelines (eg www.wikihow.com/Safely-Meet-a-Person-You-Met-Online ) and the common sense you would apply to meeting anyone new to join in sports or activities applies.

Both Julie's and Megan's examples illustrate the combined use of Facebook, Twitter, and Instagram, so it is worth remembering that different people belong to different 'tribes' online; to reach a potential audience or organiser you might need to use various methods. As described before we tell our nursing students to keep their professional Twitter accounts for professional issues. So to direct people from the very public open but professional environment of Twitter to (for example) a closed Facebook account needs a thoughtful approach as illustrated by Julie.

\section{Some resources that can help with your own health and wellbeing}

\author{
Nursing \\ https://rcni.com/ \\ https://www.facebook.com/royalcollegeofnursing/ \\ https://www.instagram.com/thercn/?hl=en \\ https://twitter.com/thercn?lang=en-gb \\ https://twitter.com/wenurses?lang=en \\ https://twitter.com/nurchat?lang=en
}

Looking after your own health and handling stress

http://www.nhs.uk/selfcare/Pages/self-care-week.aspx

https://moodgym.anu.edu.au/welcome/new/splash

http://www.llttf.com/index.php?section=page\&page seq=8

https://www.sleepio.com/

http://www.nhs.uk/conditions/stress-anxiety-depression/pages/mindfulness.aspx 
1. Nursing and Midwifery Council, The Code: Professional standards of practice and behaviour for midwives and midwives. . 2015, NMC: London. 